\title{
Video Game Design for Mobile Phones
}

\author{
Jaime Sánchez and Matías Espinoza \\ Department of Computer Science, Center for Advanced Research in Education (CARE) \\ University of Chile \\ Blanco Encalada 2120, Santiago, Chile \\ jsanchez@dcc.uchile.cl, mespinoza@c5.cl
}

\begin{abstract}
This article explores the use of mobile phones for educational purposes through the design, development and evaluation of Role Playing Games (RPG). To accomplish this, we differentiated between the functionality and design of the videogame, developing a videogame engine and videogames prototypes. Thus the engine was responsible for controlling the videogame's functionalities regarding the prototypes designed. Once designed and developed, a usability evaluation of the videogames with end-users was administered. Results show that the videogames implemented were usable, easy and pleasant to use, and that they fully motivated learners as mobile learning tools.
\end{abstract}

Keywords: cell phone, mobile, RPG, videogame, problem solving.

\section{Introduction}

Videogames have a significant educational potential, as in addition to motivating students they allow people to learn and develop skills, abilities and strategies [3]. There are wide-ranging possibilities for applying videogames to learning. Some aspects in which videogames can contribute to learning are: knowledge of digital literacy, videogame skills through problem solving, comprehension skills and academic abilities, among others [3][2].

In an RPG (Role-Playing Game) videogame, the player takes on a specific role in a storyline through a character who lives in a virtual world. The storyline develops based on the decisions and actions taken by the player during the game. The character can gain experience, specific items or other characteristics as the game develops. Through the interaction with an RPG videogame, one can take advantage of the educational potential regarding the development of skills and the learning of content by carrying out the tasks that are assigned within the videogame.

In this way, the research objective of our work is the development of an educational, RPG videogame engine for mobile cellular phones that defines the characteristics and functionalities for the various videogames that can be designed and implemented using such a platform. This is in order to obtain a tool that supports school learning through the stimulation of the user's problem solving abilities. In order to achieve this objective, a usability evaluation of two videogame prototypes created using the educational RPG videogame engine for mobile phones was carried out. 
In the following we present a review of the pertinent literature that was carried out based on the issues that make up the primary influences for our work. Afterwards, the engine and the videogames developed are described, and the evaluation of the prototypes is presented. Finally, we finish by establishing some conclusions based on our results.

\section{Literature Review}

Computers, PDAs, mobile phones and other technological artifacts all make up part of the way in which work, social relations, the creation of knowledge, learning and education have been transformed in recent decades [2]. In particular, mobile phones have been massified intensely in recent years, and the number of applications developed for these devices has increased. As a result, the general use of these applications has also become more widespread. The use of mobile phones in education can be considered as part of the evolution of the use of these devices. In addition, due to the massification of mobile phones, there is currently a student/phone ratio of almost $1: 1$, which represents a great opportunity to develop applications oriented towards education that are based on this kind of technology. Mobile phones are characterized by being light and portable, and are adequate for working while walking or even in uncomfortable places [4], and they can be used both inside and outside of the classroom. Despite their low processing speed, reduced screen size and unsatisfactory capacity for storage and volatile memory [4], these devices have what is needed to be able to manage information, generate collaboration and foment the construction of knowledge in both formal and informal situations, while being subject to the previously mentioned restrictions.

Through the use of an RPG videogame, learning activities such as imitation, feedback, training, practice, case reviews, incremental challenges and immersion can be carried out, among others [10]. Such activities involve the development of problem solving skills, specific content, and communication and concentration abilities $[6][1][7][21][5]$.

It is interesting to explore the educational potential of videogames, in which the student learns from the experiences gained through the tasks that he/she carries out within the videogame, thus breaking with the traditional teaching scheme [8][15]. This points clearly to the sense of the expectations held by children today, in that they are immersed in a world that is surrounded by technology and multimedia elements, made stronger by a high degree of interactivity. These expectations are a very important factor, which makes the traditional educational system look irrelevant to the lives of today's students. In this search for new educational media, it has been sought to attract children to learning through an RPG videogame for mobile phones, contributing to an improvement in the traditional ways of learning [10][11][12][14][13].

Conceptually speaking, doing an exercise and solving a problem are not the same. In exercises, an algorithm or routine process is applied in a mechanical manner. Solving a problem means providing a coherent explanation for a set of related information in a specific context. To do this, one must pause, reflect and even execute original actions that have not previously been practiced in order to reach a solution to the 
problem. Polya points out that problem solving is a process that implies the consideration of 4 steps [9]: 1. Comprehension and Identification of the problem; 2. Creation of a plan to solve the problem; 3 . Carrying out a plan to solve the problem; 4 . Evaluation of the solution to the problem.

In the design of an RPG videogame it is convenient to follow good practices in order to construct the storyline. With regards to this aspect, our work considers some guidelines for the creation of hyperstories [16][17], as well as a contribution to the design of the software to be developed.

Finally, some previously developed videogames were taken into account as a reference for some characteristics to consider and incorporate into the proposed engine and the videogame prototypes developed. Link [18] and The Natomy's Journey [20] are RPG videogames that present a simple level of play in which the player exchanges items during the development of the videogame in order to fulfill his/her mission in the context of an educational objective. On the other hand, BuinZoo and Museo [18] are software programs for Pocket PC and Classmate computers that consist of a quiz-type videogame that are developed while at a visit to the zoo or a museum; questions on the different issues are asked, and the information necessary to answer the questions are located within the physical environment that is being visited, which is an interesting support characteristic for a mobile phone-based videogame.

\section{The Engine and the Videogames}

The educational, RPG videogame engine developed in this study allows for the development of videogames with different themes, but identical functionalities and characteristics. In this way, the videogames were designed for individual use, and the user can navigate freely through the virtual world that the videogames offer in the available scenarios.

The engine integrates different functionalities that characterize the videogames that were developed. Of these, the most significant are:

Elements: Visually, the videogames present the user with a virtual world made up of Scenarios, in which a Main Character (the person controlled by the user) can move about freely, and in which we can find several different elements such as Characters (not controlled by the user), Items (can be used for different purposes) and Decorations (delimit and decorate the scenarios). Other elements that are visible to the user are the dialogues between the Characters, which appear as information and/or questions referring to a problem that the player needs to solve.

Interactions: When the Main Character collides with other elements in the Scenario, the following kinds of interactions can be presented: Inform, Describe, Ask, Pick up and Trade (see table 1). An interaction only occurs when there is a collision with some element in the game, and when certain conditions are met the user can change from one interaction to another, if it is available.

Playability: The engine allows the videogames to present the users with challenges, providing them with problem-solving issues, and obligating them to make decisions. 
The quality of the videogame, in this way, depends a lot on the design of the hyperstory [16]. Playability is determined by the characteristics of the Interactions together with the incorporation of problem solving aspects. Structurally, the videogame is made up of a Mission or Central Objective, which presents the player with a global problem to solve. The problem is solved when the player completes a minimum number of sequential Tasks, which are specific objectives within the videogame and which correspond to shorter-term problem-solving issues. There is a "minimum number" of Tasks because the user can simultaneously carry out other tasks in the videogame that are complementary and that are not strictly necessary in order to complete the Mission. A Task is made up of a sequence of Interactions, each of which corresponds to a node of the hyper-story.

Table 1. Possible interactions when a main character collides with the different elements

\begin{tabular}{|c|c|c|c|c|}
\hline Interaction & Description & Character & Item & Decoration \\
\hline Inform & The element provides information that is relevant to the videogame & Yes & Yes & Yes \\
\hline Describe & The element describes itself & Yes & Yes & Yes \\
\hline Pick up & $\begin{array}{l}\text { The element presents a problem that requires a certain item as a response, and awards } \\
\text { the element itself as a prize in the form of an additional item }\end{array}$ & Yes & Yes & Yes \\
\hline
\end{tabular}

\subsection{Interfaces}

\subsubsection{Screen}

The size (in pixels with dimensions $\mathrm{x}$ and $\mathrm{y}$ ) of the graphic objects on the screen is fixed, and no proportional adjustments are made when the size of the screen is smaller or larger.

The screen shows a portion of the entire Scenario, which we will denominate the clip. The size of the clip is assigned with dimensions that are the size of the display on the device, which is obtained when opening the videogame. In figure 1A we can appreciate the visible areas for different screen resolutions: Area I is for 128x128 pixel resolution, Areas I and II are for 128x160 pixel resolution, and Areas I, II and III are for $240 \times 320$ pixel resolution.

\subsubsection{Entry Buttons}

In order to keep the control of the actions within the videogame as simple as possible, we opted to use only joystick buttons, which are identified as: up button, down button, left button, right button and fire button (see figure 1B):

- Movement of the Main Character: up, down, left and right buttons.

- Continue after the Inform and Describe Interactions: fire button.

- Select one of the alternatives available in the Pick up, Trade and Respond Interactions: left and right buttons.

- Confirm a correct alternative in the Pick up, Trade and Respond Interactions: fire button.

- Perform a Scroll of the text shown in the interactions: up and down buttons. 
(A)

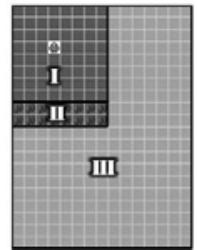

(B)

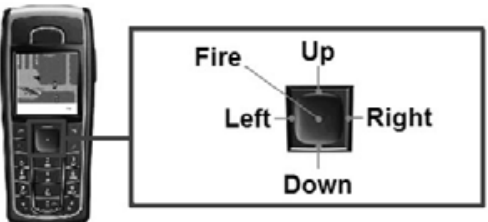

Fig. 1. (A) Clip of a scenario for different resolutions (B) Joystick buttons on a mobile phone

\subsection{Prototypes}

Two videogame prototypes were developed using the videogame engine, which we will call prototype 1 and prototype 2 .

In prototype 1 a scenario was created with a simple story involving two characters and one item. The mission consists of capturing a Cockroach, and to do so the Main Character must previously obtain a Torch, which can be obtained without any prerequisites. There is a Tortoise that asks a question once the Cockroach has been captured.

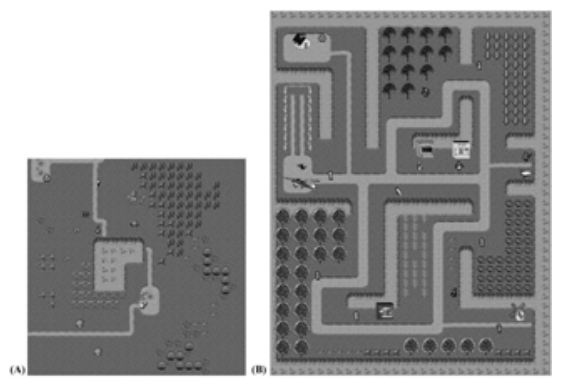

Fig. 2. Images from the maps of (A) Prototype 1 and (B) Prototype 2

In prototype 2, a visibly more extensive videogame was developed (see figure 2) with 13 characters, which involved three interactions for each one. This game developed the issue of nutrition as an educational objective. The mission for this prototype consists of getting off of an island, and to do this the player must get a pilot into an airplane. The pilot cannot get on the plane immediately because there is a dog that does not let him get near to it. Thus the pre-condition for the pilot's Interaction is to have captured the dog, and having completed this, the videogame is over. While the Main Character has still not captured the dog, the pilot presents a dialogue expressing that he cannot get close to his plane. On the other hand, the dog wants to be fed with a protein-rich food. In the videogame, three kinds of protein-rich food can be obtained: eggs, fish and meat. However, the meat is what satisfies the dog, and when he is fed a portion of meat, he is captured.

In the same way that the dog asks for his food (a protein-rich food), the other Characters ask for Items by presenting a problem consistent with each Character's need to obtain a specific food with certain nutritional characteristics. As such, the Characters provide one item in exchange for another Item, cloaking the exchange in a 
need presented as a problem, and providing clues for the answer but never asking for the Item by its specific name (see table 2 ).

Table 2. Characters and problems presented

\begin{tabular}{|l|l|}
\hline Character & \multicolumn{1}{|c|}{ Presents a problem asking for } \\
\hline Baker & Base ingredient to make bread \\
\hline Butcher & Cereal-based food that is rich in carbohydrates \\
\hline Pilot & Free the way to the plane that is blocked by the dog \\
\hline Fisherman & Vegetarian lunch rich in vitamins \\
\hline Bee Farmer & - \\
\hline Corn Girl & - \\
\hline Lettuce Girl & Sweet concentrate food \\
\hline Business Girl & Her lost hen \\
\hline Apple Boy & - \\
\hline Wind Mill Boy & Raw material needed to produce flour \\
\hline Farmer & Sweet, protein-rich food \\
\hline Dog & Protein-rich food \\
\hline Hen & Cereal-type food \\
\hline
\end{tabular}

\section{Usability Evaluation}

This evaluation was focused on the characteristics of the videogame engine, using the two previously described test prototypes.

First, prototype 1 was evaluated regarding baseline characteristics of the videogame engine such as the behavior of the interactive elements and the main character's movement, as well as the use of the most complicated controls such as the text scroll and the multiple choice selection. This was done because it was necessary to detect problems in order to redesign and improve the various aspects of the application interfaces.

Second, prototype 2 was tested by evaluating all of the characteristics of the videogame. The high number of elements and interactions in this version put the playability of the videogame to the test. For this reason, it was convenient to evaluate the level of acceptance of the videogame, and to detect design problems.

\subsection{Objectives}

The objective consisted of detecting, correcting problems with and validating the characteristics of the videogames developed using the videogame engine designed, through the evaluation of the design of the main elements, the level of playability, the use of interactive material in general, the use of controls in the main character's movements, the text scroll in the dialogues and in the selection of the multiple choice alternatives.

\subsection{Participants}

There were two groups of students from different grade-levels of general, elementary school education, with ages that fluctuated between 9 and 11 years old. Group one was made up of nine students (three girls and six boys), all of who had experience with the use of mobile phones. Group two was made up of ten students (nine girls and one boy), all of which also had previous experience using mobile phones. 
An engineer who had participated in the development of the engine and the videogames acted as an evaluator during the evaluation of the prototypes.

\subsection{Instruments}

Observation questionnaire 1: seeks to obtain a record of the actions associated with the interactions with the main elements, with which it is sought to detect problems regarding the playability and the use of the controls of the videogame. The actions recorded were: if the student asked what to do with each element, if in interacting with each element the student used the text scroll, if he/she pressed the Fire button to close the dialogue with the element, if the student pressed the Fire button for another action that had not been implemented, and if he/she performed the expected action with each element.

User feedback questionnaire: this questionnaire was inspired by some of the openended questions from the end user evaluation questionnaire for blind students [15]. In this case, the questions were centered on the elements of the prototype, asking the students if they liked each one, with possible answers of: yes, so-so, and no. In addition, some open-ended questions were incorporated, which can be seen in the results section. With these questions it was sought to evaluate the users' opinions on the design, playability, the use of the controls and the interactive material of the videogame.

End user evaluation questionnaire: consists of an adaptation of a summarized evaluation questionnaire regarding software for blind students [21], in which the specific questions designed to measure the interpretation of the sounds were replaced with questions that seek to measure the interpretation of the images. The original questions, "I like the software's sounds", "The software's sounds are clearly identifiable" and "The software's sounds provide me with information", were replaced with the questions "I like the videogame's images", "The videogame's images are clearly identifiable", and "The videogame's images provide me with information", respectively. In addition, within this questionnaire the word "software" was replaced with "videogame" wherever it appeared. This questionnaire also includes a section with open-ended questions. Through the use of this questionnaire, it is sought to evaluate the quality of the videogame based on the user's satisfaction regarding issues of design, playability, the use of controls, and the interactive material of the videogame.

Observation questionnaire 2: with the use of this questionnaire it is sought to measure the use of the functionalities, in which the evaluator answers the following questions with Yes or No regarding the user's performance: The user correctly uses the movement controls, The user navigates the map, The user interacts with the characters, The user interacts with the decorations, The user at some point uses the text scroll, The user selects the multiple choice alternatives, The user obtains the items he/she is looking for, The user understands the relation between the item sought after and the character that needs it. These questions seek to evaluate and validate the controls, the playability of the application and the interaction with the elements of the videogame.

\subsection{Procedure}

The usability tests were separated into two different moments, first to test prototype 1 with the application being developed and then to test prototype 2 with the final 
application including the changes redesigned and incorporated as a result of the first evaluation. In order to perform the usability tests, the necessary copies of the previously described instruments were printed out on paper. In addition, for both of the evaluations a Nokia 6230 mobile phone was used, with both prototype 1 and prototype 2 installed.

First the usability evaluation was applied individually in group one in the following steps: 1. Verbal instructions on what was to be done in the videogame and on the controls for the videogame were provided to each student; 2 . The interactions performed in the videogame were recorded in the observation questionnaire $1 ; 3$. When a student had doubts on what he/she had to do, instructions were provided that would allow him or her to continue playing; 4. Finally, the user feedback questionnaire was applied verbally. The evaluator read the questions out loud, and the answers were recorded on the same sheet.

Afterwards, the usability evaluation was applied individually in group two using the following steps: 1. Verbal instructions were provided to each student regarding what had to be done in the videogame, and on the controls for the videogame; 2 . Each student played for about 7 minutes; 3. The student's performance in the different functionalities were recorded in the observation questionnaire $2 ; 4$. When a student had doubts on what he/she had to do, instructions were provided that would allow him or her to continue playing; and 5. After the 7 minutes of playing time had passed, the students were invited to fill in the end user evaluation questionnaire.

\subsection{Results}

The results for the initial tests showed that the interaction with the videogame environment was highly intuitive, as very little was asked about what they had to do, and in general they were able to discover things in the videogame through exploration alone. Because of this, it was not necessary to add special guides within the videogame regarding this aspect.

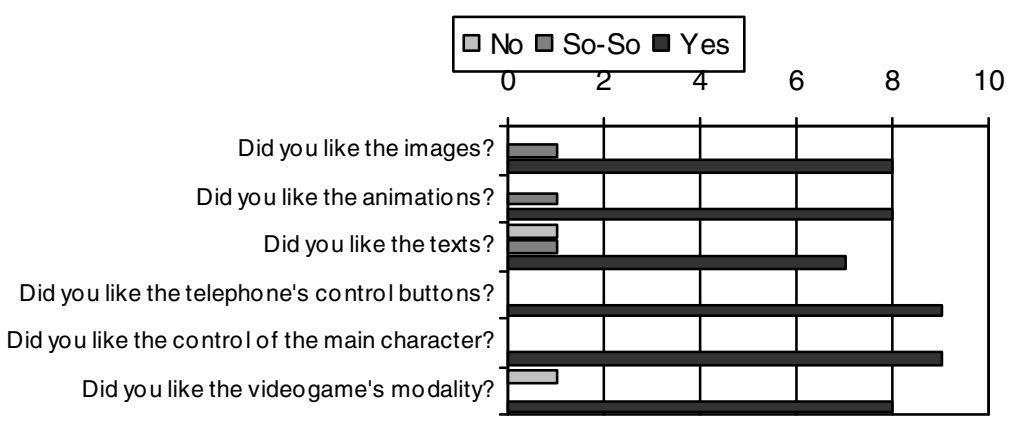

Fig. 3. Summary of the results of the user feedback questionnaire

The entry buttons for the videogame's controls and for the main character's movements were unanimously accepted (see figure 3), which provides support for the choice adopted in the videogame design. However, the use of the controls for the text scroll 
and the selection of the multiple-choice alternatives (interaction with the Tortoise) were not intuitive, as no users performed the text scroll and only two users were able to execute the action for the selection of the multiple-choice answer. For this reason, in the prototype 2 we avoided using extensive dialogues that would make it necessary to use the text scroll, and guides were added that indicated that the left and right buttons could be used to perform the selection of the multiple-choice alternatives.

The interactive elements (images, animations and texts) were well received by the students (see figure 3), for which reason we maintained the same line with regards to this aspect.

From the answers to the open-ended questions of the user feedback questionnaire, we were able to conclude that the students understood that the objective of the videogame consists of capturing the cockroach with the torch. This is good because it implies that they were able to identify a basic aspect of the game's playability, namely obtaining and using things in order to obtain other things. When asked what the videogame could be useful for, the students did not perceive any educational utility; they only expressed that it would be useful for entertainment, which presents a challenge for the second prototype in order to improve the sensation that the game leaves the users with. Also, in answering these questions the students suggested adding more trees, plants, bushes, vegetation and other elements in order to confuse the user, to be able to change characters, and increasing the difficulty of the game. This means that they wanted more interactive elements in the videogame. Faced with this scenario, for prototype 2 a more wide-ranging hyperstory was proposed, with more elements and a higher degree of complexity regarding the solution to the game, incorporating a baseline educational framework.

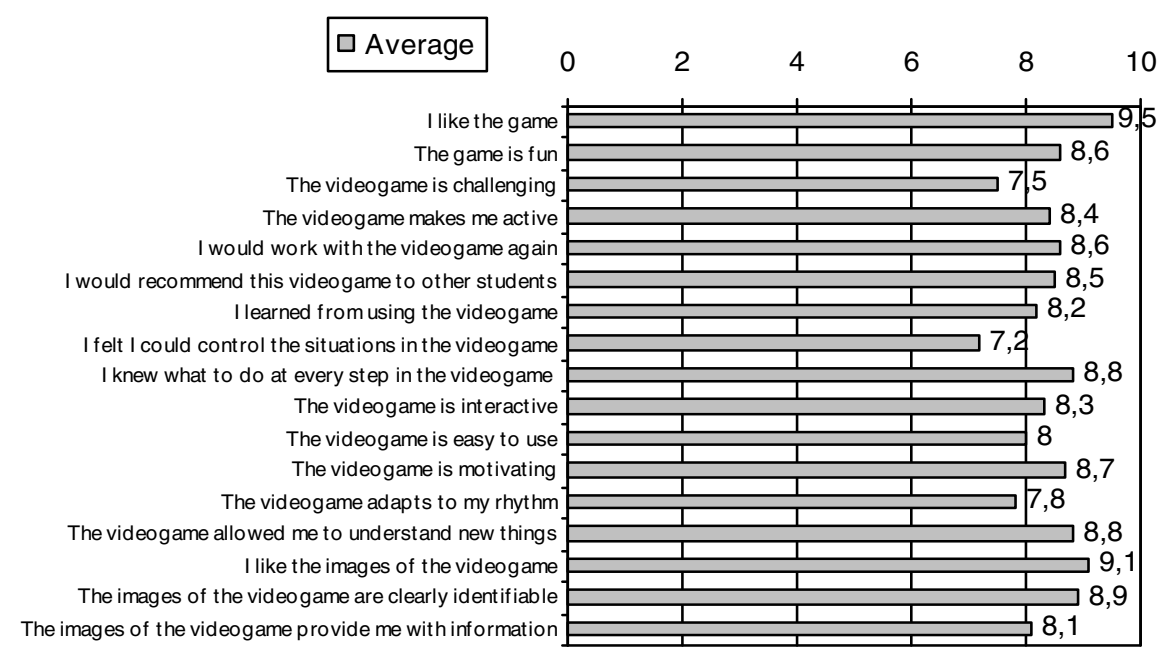

Fig. 4. Results of the end user evaluation questionnaire, showing the average percentage of each indicator on a scale of 1 to 10 points 
From the second usability tests, the results obtained from the application of the observation questionnaire 2 show that, in general, the videogames' functionalities are appropriately used by the students, according to the criteria of what was expected by the videogame designer. However, the text scroll continues to be a low point, and it is necessary to seek new ways in order to improve the use of this function.

The results collected from the end user questionnaires (see figure 4) are very good for each of the indicators of acceptance, which validates the choices regarding design, playability, and control of the videogame, in addition to the materials used.

In the answers to the questions included in the end user acceptance questionnaire, the students were shown to like various aspects of the videogame, such as "looking for the things that people ask for and need", "giving food to the dog", "providing other people with things", "the adventure format of the videogame", "the characters", "the playing fields", "helping people", and "it is fun". They also expressed their opinions on the elements of the videogame that they did not like, such as "when it was hard to find the things that people asked for", "there were no instructions", "there was no friend for the main character", and "people asked for too many things". The students suggested adding various aspects to the videogame, such as: "the characters should talk more", "the game should be bigger", "more instructions", "more characters", "more problems", "a character that helps the main character", "a pretty girl", "more things to eat" and "more elements that can do other things". They also expressed their general opinions on the videogame, with statements such as, "I liked the videogame", "it is very good", "the videogame was incredible", "it was very good", and "it is recommendable". These results show that the students had very positive feelings for the videogame, its playability and the elements that were available to them. However, the students demand a more wide-ranging and complete videogame, with more characters, more dialogues, more items and new functions, in addition to improving the videogame's instructions. When asked what the videogame could be useful for, the students answered, "to know about different harvests", "to know more about animals", "to learn", "to learn to look for things", "to learn to navigate the different parts of the videogame", "to teach", "to help", and "to discover new things". This represents a very interesting result, in that the students clearly perceive that the videogame is related to learning activities and different kinds of objectives, which represents notable progress when compared to prototype 1 .

\section{Conclusions}

In our work we successfully and satisfactorily fulfilled our objectives to design and implement an educational, RPG videogame engine. This engine offers a set of functionalities that allow for an educational, RPG videogame to be developed within it. The engine was developed and used for the creation of prototypes 1 and 2, which were tested with end users.

Another one of the proposed objectives was to support the development of the application through the usability evaluation of the educational, RPG videogames during the different stages of development. With this we were able to improve the design of the application as it was being developed, and at the same time justify design and implementation decisions that were supported by the results of the evaluations. 
The results of the usability evaluations show that the students adopted the interaction with the different elements of the videogame naturally. They were able to explore the virtual world and the possibilities offered by the videogame. This is supported by the simplicity of the choice for the videogame's controls, which represented a strong point in the evaluations regarding the facility of its use, with the exception of the text scroll, for which an acceptable improvement is still pending. Together with this aspect, the playability was also well received by the students, who understood that the dynamic of the videogame consists of providing things to the different Characters and receiving other things in exchange, being able to effectively stimulate their problemsolving abilities. Finally, we add that in general the students associated the videogame with being useful for learning-related activities. Thus, from these results we can infer that this educational, RPG videogame engine can be exploited for the development of videogames that support school learning through the stimulation of the user's problem-solving abilities.

The students' opinions from the application of the end user evaluation questionnaires showed a very high level of acceptance of the videogame, validating the choices regarding design, playability, the control of the videogame, as well as the materials used. This translates into a high level of motivation to use this tool for learning.

It is important to point out that the sample of users utilized to apply the end user evaluation questionnaire is not representative in terms of quantity. In this sense, we propose future work to evaluate such games with more users in order to assure the acceptance of the applications developed.

In addition, the usability evaluations allowed us to propose substantial improvements to the functionalities of the videogame engine. This allows the videogames developed to be more appropriate regarding the interests and ways of interacting of the end users.

Although the evaluation of the videogame engine was not the initial focus of our work, this could be an interesting aspect to evaluate in the future with a small sample of videogame designers and developers. However, the design, implementation and evaluation of the characteristics of the videogame engine used in the two prototypes involved in this project, represent guidelines that can be used by the designers and developers of educational RPG videogames for mobile phones.

We also propose future work that includes a cognitive test of the application, in order to be able to measure the effect that the use of this application has on learning. The videogame engine provides for certain aspects of learning through the available functionalities, such as the construction of questions and the presentation of information with specific content. To deal with these aspects, we intend to perform a future evaluation of the level of significance regarding the impact that the videogame engine has on users' learning. With this we would be able to completely sustain our main objective regarding the development of a tool that supports school learning through the stimulation of the user's problem-solving skills.

Acknowledgments. This report was funded by the Chilean National Fund of Science and Technology, Fondecyt \#1090352 and Project CIE-05 Program Center Education PBCT-Conicyt. 


\section{References}

1. Eriksson, Y., Gärdenfors, D.: Computer games for children with visual impairments. In: Proceedings of the 5th International Conference on Disability, Virtual Reality and Associated Technologies, New College, Oxford, UK, September 20-22, pp. 79-86 (2004)

2. Gros, B., Bernat, A.: Videojuegos y aprendizaje. Graó, Barcelona (2008)

3. Gros, B., Aguayos, J.: Pantallas, juegos y educación: La alfabetización digital en la escuela. Desclée de Brouwer, Bilbao (2004)

4. Guerrero, L., Ochoa, S., Pino, J.: Selecting Computing Devices to Support Mobile Collaboration. Group Decision and Negotiation 15(3), 243-271 (2006)

5. Kelly, H., Howell, K., Glinert, E., Holding, L., Swain, C., Burrowbridge, A., Roper, M.: How to Build Serious Games. Communication of the ACM 20(7), 45-49 (2007)

6. Klopfer, E., Yoon, S.: Developing Games and Simulations for Today and Tomorrow's tech Savvy Youth TechTrends. Linking Research \& Practice to Improve Learning 49(3), 33-41 (2005)

7. McDonald, K., Hannafin, R.: Using web-based computer games to meet the demands of today's high stakes testing: A mixed method inquiry. Journal of Research on Technology in Education 55(4), 459-472 (2003)

8. McMichael, A.: PC Games and the Teaching of History. The History Teacher 40(2), 203218 (2007)

9. Polya, G.: How to solve it. Doubleday and Co., Inc., Garden City (1957)

10. Prensky, M.: Digital Game-Based Learning. McGraw-Hill, New York (2001)

11. Prensky, M.: Digital Natives. Digital Immigrants Part 1: On The Horizon - The Strategic Planning Resource for Education Professionals 9(5), 1-6 (2001)

12. Prensky, M.: Digital Natives. Digital Immigrants Part 2: Do They Really Think Differently? On the Horizon 9(6), 1-6 (2001)

13. Prensky, M.: Engage Me or Enrage Me: What Today's Learners Demand. Educause Review 40(5), 60, 62,64 (2005)

14. Prensky, M.: Listen to the Natives. Educational Leadership 63(4), 8-13 (2006)

15. Proserpio, L., Viola, D.: Teaching the virtual generation. Academy of Management Learning \& Education 6(1), 69-80 (2007)

16. Lumbreras, M., Sánchez, J.: Hyperstories: A model to specify and design interactive educational stories. In: En Baeza, R. (ed.) Computer Science, USA, pp. 135-146. Editorial IEEE Computer Society, Los Alamitos (1997)

17. Sánchez, J., Lumbreras, M., Bibbo, L.: Hyperstories for learning. In: En Nanard, M. (ed.) Workshop in Computing, Hypermedia Design. Springer, Heidelberg (1996), ISBN 3-540199-85-3

18. Sánchez, J., Elías, M.: Science Learning in Blind Children through Audio-Based Games. In: Redonde, M., Bravo, C., Ortega, M. (eds.) Engineering the User Interaction: From Research to Practice, pp. 87-102. Springer, London (2008)

19. Sánchez, J., Mendoza, C., Salinas, A.: Mobile serious games for collaborative problem solving. In: Brenda, K. (ed.) Wiederhold and Giuseppe Riva (Editors) the Annual Review of Cybertherapy and Telemedicine 2009. Studies in Health Technology and Informatics (SHTI) Series, vol. 144, pp. 193-197. IOS Press, Amsterdam (2009)

20. Sánchez, J., Sáenz, M.: Video Gaming for Blind Learners School Integration in Science Classes. In: Gross, T., Gulliksen, J., Kotzé, P., Oestreicher, L., Palanque, P., Prates, R.O., Winckler, M. (eds.) INTERACT 2009, Part I. LNCS, vol. 5726, pp. 36-49. Springer, Heidelberg (2009)

21. Sánchez, J., Salinas, A., Sáenz, M.: Mobile Game-Based Methodology for Science Learning. In: Jacko, J.A. (ed.) HCI 2007, Part IV. LNCS, vol. 4553, pp. 322-331. Springer, Heidelberg (2007)

22. Sanchez, J.: End-user and facilitator questionnaire for Software Usability. In: Usability Evaluation Test. University of Chile, Santiago (2003) 